\title{
Systematic donor selection review process improves cardiac transplant volumes and outcomes
}

\author{
Jason W. Smith, MD, ${ }^{\mathrm{a}}$ Kevin D. O'Brien, MD, ${ }^{\mathrm{b}}$ Todd Dardas, MD, ${ }^{\mathrm{b}}$ Jay D. Pal, MD, PhD, ${ }^{\mathrm{a}}$ \\ Daniel P. Fishbein, MD, ${ }^{b}$ Wayne C. Levy, MD, ${ }^{b}$ Claudius Mahr, DO, ${ }^{b}$ Sofia C. Masri, MD, ${ }^{b}$ \\ Richard K. Cheng, MD, ${ }^{b}$ April Stempien-Otero, MD, ${ }^{b}$ and Nahush A. Mokadam, MD
}

\begin{abstract}
Background: Heart transplant remains the definitive therapy for advanced heart failure patients but is limited by organ availability. We identified a large number of donor hearts from our organ procurement organization $(\mathrm{OPO})$ being exported to other regions.

Methods: We engaged a multidisciplinary team including transplant surgeons, cardiologists, and our OPO colleagues to identify opportunities to improve our center-specific organ utilization rate. We performed a retrospective analysis of donor offers before and after institution of a novel review process.

Results: Each donor offer made to our program was reviewed on a monthly basis from July 2013 to June 2014 and compared with the previous year. This review process resulted in a transplant utilization rate of $28 \%$ for period 1 versus $49 \%$ for period $2(P=.007)$. Limiting the analysis to offers from our local OPO changed our utilization rate from $46 \%$ to $75 \%(P=.02)$. Transplant volume increased from 22 to 35 between the 2 study periods. Thirty-day and 1-year mortality were unchanged over the 2 periods. A total of 58 hearts were refused by our center and transplanted at other centers. During period 1, the 30-day and 1-year survival rates for recipients of those organs were $98 \%$ and $90 \%$, respectively, comparable with our historical survival data.
\end{abstract}

Conclusions: The simple process of systematically reviewing donor turndown events as a group tended to reduce variability, increase confidence in expanded criteria for donors, and resulted in improved donor organ utilization and transplant volumes. (J Thorac Cardiovasc Surg 2016;151:238-43)

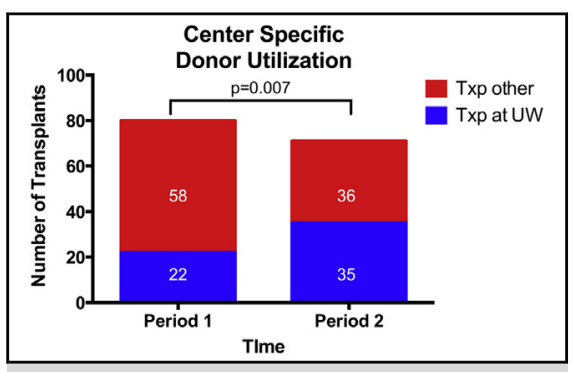

Graph showing an increase in heart utilization at our center despite a decrease in overall donors.

\section{Central Message}

Improving quality in donor selection can markedly increase transplant volume without compromising safety and quality.

\section{Perspective}

Heart transplant remains the gold standard treatment for end-stage heart failure, but is limited by donor availability, which has remained unchanged for 3 decades. We engaged in a donor selection review process to better understand our organ utilization and found that improving the consistency of donor selection improved our volumes and maintained outcomes, improving stewardship of a precious resource.

See Editorial Commentary page 243.
It is estimated that more than 6 million people in the United States suffer from heart failure, with 10 new diagnoses each year for every 1000 persons. ${ }^{1}$ Orthotopic heart transplantation (OHT) remains the gold standard for end-stage heart failure in eligible patients. ${ }^{2,3}$ Transplant volumes in the US have remained static over the last 15 years at

From the ${ }^{\mathrm{a}}$ Division of Cardiothoracic Surgery, Department of Surgery, and ${ }^{\mathrm{b}}$ Division of Cardiology, University of Washington, Seattle, Washington.

Read at the 41st Annual Meeting of The Western Thoracic Surgical Association, Whistler, British Columbia, Canada, June 24-27, 2015.

Received for publication June 25, 2015; revisions received Aug 7, 2015; accepted for publication Aug 22, 2015; available ahead of print Sept 29, 2015.

Address for reprints: Jason W. Smith, MD, Division of Cardiac Surgery, Department of Surgery, University of Washington, 1959 NE Pacific St 356310, Seattle, WA 98195 (E-mail: jwsmith@uw.edu).

0022-5223/\$36.00

Copyright (c) 2016 by The American Association for Thoracic Surgery

http://dx.doi.org/10.1016/j.jtcvs.2015.08.081 approximately 2000 per year, ${ }^{4}$ largely due to decreasing rates of violent death, stricter seat belt and helmet legislation, improved airbag technology, and overall improvement in the trauma infrastructure. ${ }^{5,6}$ Owing to excellent long-term outcomes with OHT, many centers have proposed expanding the donor pool by considering organs from donors of older age, with increased infectious disease risk, with coronary artery disease, with left ventricular hypertrophy, with decreased ejection fraction, and others. ${ }^{7-10}$ Interestingly, however, despite this success, donor utilization rates have decreased nationwide. ${ }^{11,12}$ This decrease may be related to the increased use of left ventricular assist devices as a bridge to transplant, with these patients more stable than their inotrope-dependent counterparts. ${ }^{13}$ In addition, because of stable volumes, along with increased public scrutiny of outcomes, many centers may have evolved a riskaverse donor utilization scheme. 


\section{Abbreviations and Acronyms \\ $\mathrm{CDC}=$ Center for Disease Control \\ $\mathrm{CDC}-\mathrm{HR}=$ Centers for Disease Control and Prevention high-risk \\ OHT = Orthotopic heart transplant(ion) \\ OPO = Organ procurement organization \\ UNOS = United Network for Organ Sharing}

A review of the donor heart export rate in our organ procurement organization (OPO) found it higher than expected. In an effort to better understand organ utilization by our OPO and our center, we initiated a quality improvement initiative to examine this in detail. This study examines the donor utilization process at a single, moderate-volume center.

\section{METHODS}

The Institutional Review Board at the University of Washington granted approval for this study. A multidisciplinary group of transplant surgeons and cardiologists was assembled in collaboration with our local OPO. Retrospectively, all donor offers from July 2012 to June 2013 (period 1) were systematically reviewed. Along with demographic data, clinical parameters were captured from DonorNet, and refusal codes were collated. All organs refused by our center and subsequently transplanted elsewhere were analyzed to determine the presence of a potential candidate at our institution who was within a reasonable size range $( \pm 30 \%)$, devoid of unacceptable antigens, and in a position on the match run list to accept the organ.

From July 2013 through June 2014 (period 2), the multidisciplinary group implemented our quality improvement analysis of donor utilization. Using similar methodology, demographic data, clinical parameters, and refusal codes were analyzed. In addition, real-time rationales were captured at the time of organ refusal. The multidisciplinary group reviewed all organ refusals on a quarterly basis in a nonconfrontational setting. All of the refused organs that were ultimately transplanted and met the foregoing criteria were brought to a full quorum for open discussion. The review process was then continued as a regular element in our transplant program quality assessment program. The review process was facilitated to provide a constructive environment to encourage the development of best practices and consistency. Specific attention was given to pertinent literature to support decision making, and short-term outcomes on declined organs were obtained from the United Network for Organ Sharing report on organs offered to our center but transplanted elsewhere.

\section{Statistical Analysis}

All data were analyzed using the Prism 6 statistical software package (GraphPad Software, La Jolla, Calif). Continuous variables were recorded as means and compared using an unpaired Student $t$ test. categorical variables were compared using Fisher's exact test, owing to the small sample sizes. A $P$ value $\leq .05$ was used to determine the level of statistical significance. All reported $P$ values are 2-sided.

\section{RESULTS}

\section{Donor Characteristics}

Over the period of review, 6 cardiac surgeons and 8 transplant cardiologists actively participated in donor selection. During period 1, there were 293 total heart offers, and 132 hearts were transplanted at any center. During period 2, there were 279 total heart offers, and 129 were transplanted at any center. Donor demographics and clinical parameters are presented in Table 1. Donor characteristics were similar in hearts transplanted at our institution and those transplanted at other institutions after our refusal across both time periods. Only 2 donor characteristics were statistically significantly different between the 2 groups: donor height was greater in our group $(174-177 \mathrm{~cm}$ vs $169-170 \mathrm{~cm}$; $P=.04$ for period 1 , and $P=.003$ for period 2), and there was a higher incidence of gunshot wounds as an etiology of donor death in organs accepted at our institution versus those accepted elsewhere during period $1(P=.03)$.

\section{Donor Utilization}

During period 1, of the 132 transplanted hearts, 80 were available to recipients at our institution with no provisional acceptance, with an appropriate size match, and without unacceptable antigens. Twenty-two transplants were performed by our center, yielding a center specific donor utilization rate of $28 \%$. In period 2, 71 of the 129 transplanted hearts were available to recipients at our institution with similar characteristics. Thirty-five transplants were performed, yielding a significantly higher donor utilization rate of $49 \%(P=.007)$ (Figure 1$)$. This increase in volume was sustained over the next year, July 2014 to June 2015, with volumes increasing again to 43 transplants. Survival data are not yet available for this time period. Over this same later period, the total number of offers declined again, to 222 . Of those hearts, 132 were ultimately transplanted at some institution, and of those 71 were available to our institution based on the foregoing criteria. This yielded a center utilization rate of $61 \%$. The vast majority of hearts transplanted at our institution originated within our OPO.

There was a statistically significant decrease in the rate of organ export over the 2 time periods. A total of 21 exports and 18 hearts were accepted and transplanted at our institution during period 1, compared with 9 and 27, respectively, during period 2. This represents an improvement in centerspecific, OPO-limited utilization rate from $46 \%$ in period 1 to $75 \%$ in period $2(P=.02)$ (Figure 2$)$.

From the OPO perspective, in period 1 there were 77 heart offers and 45 were accepted for transplant, for an OPO utilization rate of $58.4 \%$. During period 2, there were 61 heart offers and 40 acceptances, for an OPO utilization rate of $65.6 \%(P=.40)$.

\section{Refusal Codes}

We attempted to assess the variation in utilization of refusal codes. Although there was no statistical difference between the 2 periods in the use of refusal codes, there was a trend toward decreased use of codes for donor age/ quality, from $39 \%$ to $32 \%(P=.15)$ and donor social history, from $8 \%$ to $5 \%$. From period 1 to period 2 , there was a 
TABLE 1. Donor characteristics

\begin{tabular}{|c|c|c|c|c|c|c|c|c|}
\hline \multirow[b]{2}{*}{ Donor characteristic } & \multicolumn{2}{|c|}{$\begin{array}{c}\text { Donors accepted } \\
\text { for transplant }\end{array}$} & \multirow[b]{2}{*}{$\begin{array}{c}P \text { value, } \\
\text { I vs II }\end{array}$} & \multicolumn{2}{|c|}{$\begin{array}{c}\text { Donors available to } \\
\text { our center but refused }\end{array}$} & \multirow[b]{2}{*}{$\begin{array}{l}P \text { value, } \\
\text { III vs IV }\end{array}$} & \multirow[b]{2}{*}{$\begin{array}{c}P \text { value, I } \\
\text { vs III }\end{array}$} & \multirow[b]{2}{*}{$\begin{array}{l}P \text { value } \\
\text { II vs IV }\end{array}$} \\
\hline & $\begin{array}{c}\text { I } \\
\text { Period 1 } \\
(n=22) \\
\end{array}$ & $\begin{array}{c}\text { II } \\
\text { Period } 2 \\
(n=35) \\
\end{array}$ & & $\begin{array}{c}\text { III } \\
\text { Period 1 } \\
(n=58) \\
\end{array}$ & $\begin{array}{c}\text { IV } \\
\text { Period } 2 \\
(n=36) \\
\end{array}$ & & & \\
\hline Age, $y$, mean & 32.5 & 28.7 & .22 & 35.2 & 33.9 & .66 & .39 & .10 \\
\hline Male sex, n (\%) & $15(68)$ & $28(80)$ & .36 & $34(59)$ & $21(58)$ & 1.00 & .61 & .07 \\
\hline Height, $\mathrm{cm}$, mean & 174 & 177 & .28 & 169 & 170 & .67 & .04 & .003 \\
\hline Weight, kg, mean & 78.9 & 85.3 & .14 & 76.8 & 84.6 & .11 & .66 & .89 \\
\hline Body mass index, mean & 25.9 & 27.3 & .33 & 26.9 & 29.4 & .13 & .51 & .24 \\
\hline \multicolumn{9}{|l|}{ ABO class, $n(\%)$} \\
\hline $\mathrm{O}$ & $12(54)$ & $18(51)$ & 1.00 & $30(52)$ & $15(42)$ & .40 & 1.00 & .48 \\
\hline A & $7(32)$ & $14(40)$ & .58 & $16(28)$ & $16(44)$ & .12 & .78 & .81 \\
\hline $\mathrm{B}$ & $3(14)$ & $3(9)$ & .67 & $12(20)$ & $5(14)$ & .58 & .54 & .71 \\
\hline $\mathrm{AB}$ & 0 & 0 & - & 0 & 0 & - & - & - \\
\hline \multicolumn{9}{|l|}{ Cause of death, $\mathrm{n}(\%)$} \\
\hline Intracranial hemorrhage & $2(9)$ & $3(9)$ & 1.00 & $13(22)$ & $10(28)$ & .62 & .22 & .06 \\
\hline Closed head injury & $9(41)$ & $12(34)$ & .78 & $15(26)$ & $7(20)$ & .62 & .27 & .19 \\
\hline Gunshot wound & $9(41)$ & $6(17)$ & .07 & $9(16)$ & $3(8)$ & .36 & .03 & .33 \\
\hline Asphyxiation & $1(4.5)$ & $7(20)$ & .13 & $4(7)$ & $3(8)$ & 1.00 & 1.00 & .19 \\
\hline Drug intoxication & $1(4.5)$ & $5(14)$ & .39 & $11(19)$ & $4(11)$ & .39 & .16 & .74 \\
\hline Other & 0 & $2(6)$ & .52 & $6(10)$ & $9(25)$ & .08 & .18 & .05 \\
\hline Ejection fraction, $\%$, mean & 64.5 & 62.3 & .11 & 63.3 & 62.8 & .70 & .36 & .76 \\
\hline CPR performed, n (\%) & $7(32)$ & $18(51)$ & .18 & $25(43)$ & $21(58)$ & .39 & .44 & .64 \\
\hline CDC-HR, n (\%) & $3(14)$ & $6(17)$ & 1.00 & $9(16)$ & $7(19)$ & .78 & 1.00 & 1.00 \\
\hline
\end{tabular}

$C P R$, Cardiopulmonary resuscitation; $C D C$ - $H R$, Centers for Disease Control and Prevention high-risk.

nonsignificant increase in donors with a Centers for Disease Control and Prevention (CDC) high-risk designation (CDCHR) transplanted at our institution ( 3 vs $6 ; P=1.0)$. There was also a trend toward increased utilization of donors who underwent cardiopulmonary resuscitation, from $32 \%$ of the donors in period 1 to $51 \%$ in period $2(P=.18)$. At the same time, there was an increase in use of the donor/recipient size mismatch code and the code for "other," with an option to write in reasons during the second period.

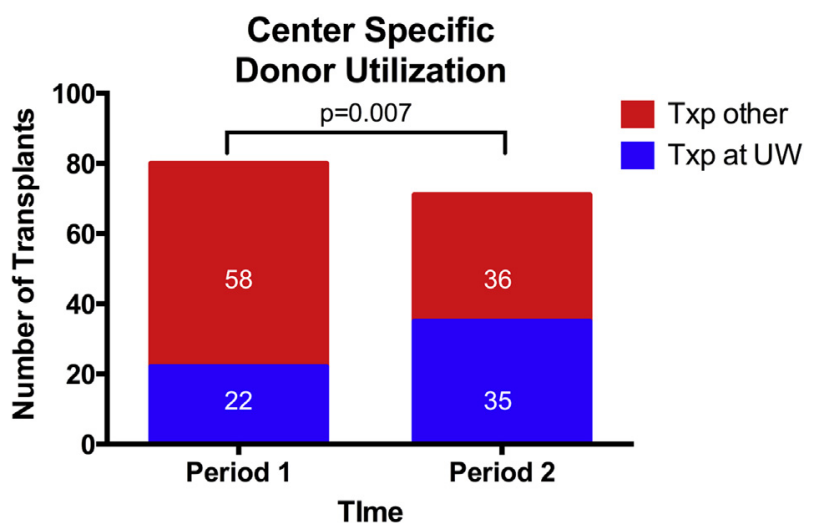

FIGURE 1. Center-specific donor utilization in periods 1 and 2, showing increasing utilization of available donor organs despite decreasing numbers of overall donors. $U W$, University of Washington.

\section{Transplant Outcomes}

A review of our transplant outcomes over the duration of the study revealed no significant difference in 30-day or 1year mortality between period 1 and period $2(P=.38$ and .67 , respectively) (Table 2). Using the United Network for Organ Sharing (UNOS) report, we were able to ascertain the function of organs that we refused but were ultimately transplanted elsewhere. We found follow-up data on 46 of the 58 hearts that were refused. The 30-day mortality was

\section{Exported Hearts from Local OPO}

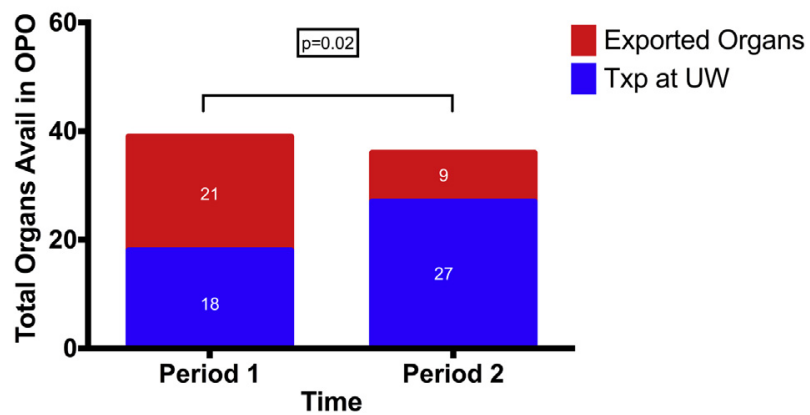

FIGURE 2. A reduction in the number of exported hearts from our local region from 21 to 9 accounted for most of the increased transplant volume at our center. $U W$, University of Washington; $O P O$, organ procurement organization. 
TABLE 2. Transplant outcomes for recipients who underwent transplantation at our institution demonstrating that outcomes by these measures were unchanged despite increasing utilization

\begin{tabular}{lccc}
\hline \multicolumn{1}{c}{ Measure } & Period 1 & Period 2 & $\boldsymbol{P}$ value \\
\hline Number & 22 & 35 & .22 \\
Total ischemic time, min, mean & 244.7 & 244.9 & .99 \\
Mechanical circulatory support, n (\%) & $2(9)$ & $5(14)$ & .69 \\
30-d mortality, n (\%) & $3(14)$ & $2(6)$ & .38 \\
1 year mortality, n (\%) & $3(14)$ & $3(9)$ & .67 \\
\hline
\end{tabular}

$2 \%$, and 1 -year mortality was $10 \%$ (Figure 3 ). Owing to the delay in reporting outcomes with the UNOS offer report, we were able to obtain follow-up only for the recipients from other centers from period 1 . The outcomes of patients on the waiting list at our center were also reviewed and we found a $17.2 \%$ mortality during period 1 and $12.0 \%$ mortality for period $2(P=.50)$.

\section{DISCUSSION}

Because of the scarcity of donor organs, there is a worldwide imperative to maximize the utilization of suitable donors. The assessment of donor quality for heart transplantation remains an area of controversy and investigation. ${ }^{9,14}$ Programs have examined a multitude of donor factors in an attempt to expand the donor pool. ${ }^{9,15}$ Average donor age has increased over the last 20 years from a mean of 29 years to a peak of 33, followed by a drop to the current 31 years. ${ }^{12}$ This is driven in part by an increase in the acceptable upper limit of donor age from 40 years to 50 years and even into the mid-60s in some aggressive centers. ${ }^{16-19}$ The use of CDC-HR donors has also been championed owing to the low risk of transmission with contemporary testing methods. ${ }^{20}$ Studies of donor use of illicit drugs has also been investigated revealing that both remote and current narcotic use has no effect on transplant outcomes. ${ }^{20}$ The use of methamphetamine- and cocainepositive donors historically has been more controversial, but an emerging body of work affirms the safety of using carefully selected donors who are users of these substances. $^{21-23}$ Cardiopulmonary resuscitation in donors with return to normal function has not demonstrated adverse outcomes, and longer total ischemic time may be more acceptable than previously thought. ${ }^{24-26}$ The impact of left ventricular hypertrophy on donor quality is also facing scrutiny, and may be less restrictive than historically assumed. ${ }^{27}$

Although the changes in the use of donor organs with each of these individual high-risk donor characteristics were not statistically significant at our center, the vector of change was in the direction of using more of these organs, which we feel accounts for the behavioral adaptation that has led to increased transplant volumes. There is a dedicated body of literature testifying to potential expansion

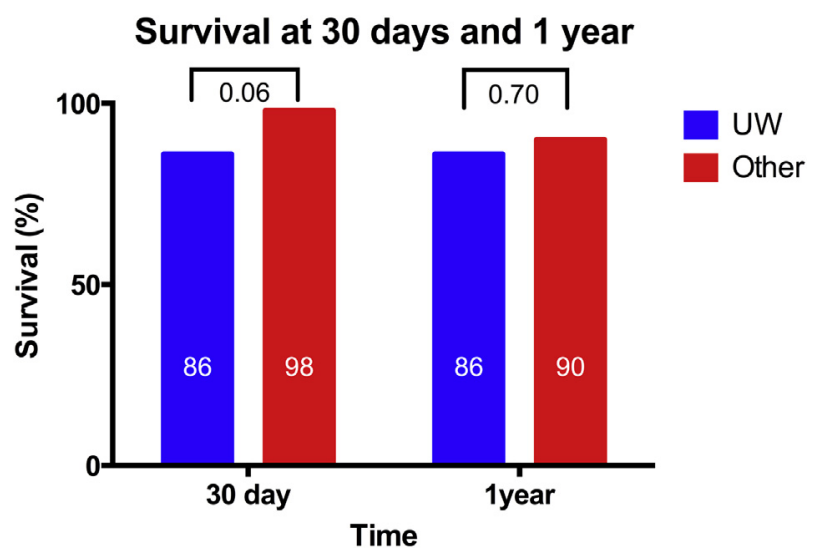

FIGURE 3. Survival at 30 -days and at 1 -year for our patients in period 1 compared with patients who received hearts that we refused over the same time frame. Only period 1 is reviewed to have sufficient follow-up for 1 year survival. $U W$, University of Washington.

of the donor pool and increasing our use of this precious resource. With that in mind, it remains somewhat surprising that no global increase in the donor pool has been seen in more than 3 decades. ${ }^{3}$ Some of that lack of growth is related to the decreasing numbers of high-quality donors from public health initiatives, as well as to improved acute neurologic care that may prevent progression to brain death. ${ }^{28}$

The individual decision to use or discard a donor organ is one of the most challenging aspects of transplant medicine. It requires balancing donor risks against the exigencies of the recipient. We found a large number of hearts being exported from our OPO. By engaging in a systematic, proactive quality improvement process to examine this specific aspect, we were able to increase our use of hearts within our area from $46 \%$ to $75 \%$, thereby increasing our transplant volume despite the fact that there were fewer total donor offers in period 2 of our study. Moreover, the use of organs from our local OPO increased over the study period, from $58.4 \%$ in period 1 to $65.6 \%$ in period 2 . Although this was not a statistically significant increase, larger study numbers may bear out this trend.

This finding suggests that the local OPO continues to identify high-quality donor organs, and that our volume increase is related to a higher utilization rate rather than to an increase in supply. Our waitlist mortality decreased from $17 \%$ to $12 \%$ over the course of the study, which, although not statistically significant, does indicate that increasing use of organs that may be outside of the usual pattern is associated with a trend toward improved waitlist survival and needs to be considered when assessing donor hearts. As transplant lists continue to grow in the face of stagnating availability of donor organs, other technologies have sought to make inroads to meet the growing demand. Until ventricular assist devices begin to approach the long-term survival of OHT, we need to continue to carefully assess every available heart. ${ }^{29}$ 
This quality improvement process was born out of a close collaboration between cardiology and cardiac surgery programs. We were able to conduct these reviews in an open and collegial manner that ignited excitement about the potential expansion of our program and providing a service to an ever-growing patient population. We also found the sessions to be educationally rich for trainees, who prompted a heart failure journal club to review transplant- and donor-related literature. This collegial atmosphere is essential to the success of this type of initiative and reflects common practice in many advanced heart failure programs.

Moving forward, our center continues to deliberately evaluate each heart offer. Although our donor utilization has increased dramatically, opportunities for further growth remain. We took more care when considering hearts refused by multiple centers, which we ultimately accepted and successfully transplanted. Further investigations into gender and size matching may be worthwhile, and increased consideration of older donors may be reasonable. Finally, there was a significant number of hearts not ultimately transplanted by any center. This represents a large, untapped pool of potential donor hearts that might add to the net number of transplants performed nationally and not merely redistribute organs. A better understanding of the reasons why these hearts are refused for transplantation may allow us to identify opportunities to rescue some of these discarded organs. We plan to continue this effort by examining discarded organs in our region and evaluating factors or technologies that might help differentiate between unusable organs and those available for transplant.

\section{CONCLUSIONS}

We systematically examined our center's donor utilization practices using a nonconfrontational, proactive multidisciplinary approach. Through judicious use of relevant literature and frank discussion regarding individual and group bias, we were able to successfully reduce variability and increase our center-specific donor utilization. This resulted in increased transplant volumes at our program despite a decreasing donor pool and with no increase in perioperative morbidity or mortality.

\section{Conflict of Interest Statement}

Dr Smith is a consultant for Thoratec and is a primary site investigator for the EXPAND Trial sponsored by TransMedics. Dr Dardas is supported by the American College of Cardiology/Daiichi Sankyo Career Development Award. Dr Pal reports grant support from Tenax. Dr Levy is a consultant for HeartWare, Novartis, GE Healthcare, Pharmin, and Biotronik. Dr Mahr is a consultant for Thoratec, HeartWare, and Abiomed. Dr Mokadam is a consultant for Thoratec, HeartWare, Syncardia, and St Jude Medical, and is the recipient of research grants from Thoratec,
HeartWare, and Syncardia. All other authors have nothing to disclose with regard to commercial support.

We would like to credit the collaborative efforts of our organ procurement organization, LifeCenter Northwest, Bellevue, Washington. All staff members at LifeCenter Northwest have demonstrated their dedication to improving organ transplant in our region. Kevin O'Connor and Candy Wells deserve special mention for their instrumental role in accessing the data to help our center develop the quality improvement process that led to the increased utilization of donor organs in our region.

\section{References}

1. Roger VL, Go AS, Lloyd-Jones DM, Benjamin EJ, Berry JD, Borden WB, et al. Heart disease and stroke statistics-2012 update: a report from the American Heart Association. Circulation. 2012;125:e2-220.

2. John R, Rajasinghe H, Chen JM, Weinberg AD, Sinha P, Itescu S, et al. Impact of current management practices on early and late death in more than 500 consecutive cardiac transplant recipients. Ann Surg. 2000;232:302-11.

3. Stehlik J, Edwards LB, Kucheryavaya AY, Benden C, Christie JD, Dobbels F, et al. The registry of the International Society for Heart and Lung Transplantation: twenty-eighth adult heart transplant report-2011. J Heart Lung Transplant. 2011;30:1078-94.

4. Lund LH, Edwards LB, Kucheryavaya AY, Benden C, Christie JD, Dipchand AI, et al. The registry of the International Society for Heart and Lung Transplantation: thirty-first official adult heart transplant report-2014. J Heart Lung Transplant. 2014;33:996-1008.

5. Centers for Disease Control and Prevention; National Center for Injury Prevention and Control. Web-Based Injury Statistics Query and Reporting System (WISQARS). Available at: http://www.cdc.gov/injury/wisqars/index.html. Accessed March 14, 2013.

6. Department of Justice, Federal Bureau of Investigation. Uniform crime reports. Available at: https://www.fbi.gov/about-us/cjis/ucr/crime-in-the-u.s/2011/crimein-the-u.s.-2011. Accessed June 21, 2015.

7. Forni A, Luciani GB, Chiominto B, Pizzuti M, Mazzucco A, Faggian G. Results with expanded donor acceptance criteria in heart transplantation. Transplant Proc. 2011;43:953-9.

8. Zaroff JG, Rosengard BR, Armstrong WF, Babcock WD, D’Alessandro A, Dec GW, et al. Consensus conference report. Mmaximizing use of organs recovered from the cadaver donor: cardiac recommendations, March 28-29, 2001, Crystal City, VA. Circulation. 2002;106:836-41.

9. Chen JM, Sinha P, Rajasinghe HA, Suratwala SJ, McCue JD, McCarty MJ, et al. Do donor characteristics really matter? Short- and long-term impact of donor characteristics on recipient survival, 1995-1999. J Heart Lung Transplant. 2002;21:608-10.

10. Khush KK, Menza R, Nguyen J, Zaroff JG, Goldstein BA. Donor predictors of allograft use and recipient outcomes after heart transplantation. Circ Heart Fail. 2013;6:300-9.

11. Khush KK, Zaroff JG, Nguyen J, Menza R, Goldstein BA. National decline in donor heart utilization with regional variability: 1995-2010. Am J Transplant. 2015;15:642-9.

12. Nativi JN, Brown RN, Taylor DO, Kfoury AG, Kirklin JK, Stehlik J. Temporal trends in heart transplantation from high-risk donors: are there lessons to be learned? A multi-institutional analysis. J Heart Lung Transplant. 2010;29: 847-52.

13. Kirklin JK, Naftel DC, Kormos RL, Stevenson LW, Pagani FD, Miller MA, et al. The fourth INTERMACS annual report: 4000 implants and counting. J Heart Lung Transplant. 2012;31:117-26.

14. Stehlik J, Feldman DS, Brown RN, VanBakel AB, Russel SD, Ewald GA, et al. Interactions among donor characteristics influence post-transplant survival: a multi-institutional analysis. J Heart Lung Transplant. 2010;29:291-8.

15. Khasati NH, Machaal A, Barnard J, Yonan N. Donor heart selection: the outcome of "unacceptable" donors. J Cardiothorac Surg. 2007;2:13.

16. Chin C, Miller J, Robbins R, Reitz B, Bernstein D. The use of advanced-age donor hearts adversely affects survival in pediatric heart transplantation. Pediatr Transplant. 1999;3:309-14.

17. Blanche C, Kamlot A, Blanche DA, Kearney B, Magliato KE, Czer LS, et al. Heart transplantation with donors fifty years of age and older. J Thorac Cardiovasc Surg. 2002;123:810-5. 
18. Costanzo MR, Dipchand A, Starling R, Anderson A, Chan M, Desai S, et al. The International Society of Heart and Lung Transplantation guidelines for the care of heart transplant recipients. J Heart Lung Transplant. 2010;29:914-56.

19. Lietz K, John R, Mancini DM, Edwards NM. Outcomes in cardiac transplant recipients using allografts from older donors versus mortality on the transplant waiting list: implications for donor selection criteria. J Am Coll Cardiol. 2004:43:1553-61.

20. Shea KJ, Sopko NA, Ludrosky K, Hoercher K, Smedira NG, Taylor DO, et al. The effect of a donor's history of active substance abuse on outcomes following orthotopic heart transplantation. Eur J Cardiothorac Surg. 2007;31:452-6.

21. Brieke A, Krishnamani R, Rocha M, Li W, Patten RD, Konstam MA, et al. Influence of donor cocaine use on outcome after cardiac transplantation: analysis of the United Network for Organ Sharing Thoracic Registry. J Heart Lung Transplant. 2008;27:1350-2.

22. Jayarajan S, Taghavi S, Komaroff E, Shiose A, Schwartz D, Hamad E, et al. Long-term outcomes in heart transplantation using donors with history of past and present cocaine use. Eur J Cardiothorac Surg. 2015;47:e146-50.

23. Freimark D, Czer LS, Admon D, Aleksic I, Valenza M, Barath P, et al. Donors with a history of cocaine use: effect on survival and rejection frequency after heart transplantation. J Heart Lung Transplant. 1994:13:1138-44.

24. Quader MA, Wolfe LG, Kasirajan V. Heart transplantation outcomes from cardiac arrest-resuscitated donors. J Heart Lung Transplant. 2013;32:1090-5.
25. Morgan JA, John R, Weinberg AD, Kherani AR, Colletti NJ, Vigilance DW, et al Prolonged donor ischemic time does not adversely affect long-term survival in adult patients undergoing cardiac transplantation. J Thorac Cardiovasc Surg. 2003;126:1624-33.

26. Smith JW, O'Brien KD, Dardas TF, Fishbein DP, Verrier ED, Stempien-Otero A et al. Excellent long-term survival with extended ischemic time in orthotopic heart transplantation. J Heart Lung Transplant. 2014;33:s117-8.

27. Goland S, Czer LS, Kass RM, Siegel RJ, Mirocha J, De Robertis MA, et al. Use of cardiac allografts with mild and moderate left ventricular hypertrophy can be safely used in heart transplantation to expand the donor pool. J Am Coll Cardiol. 2008;51:1214-20.

28. Kramer AH, Zygun DA, Doig CJ, Zuege DJ. Incidence of neurologic death among patients with brain injury: a cohort study in a Canadian health region. CMAJ. 2013;185:E838-45.

29. Stevenson LW. Crisis awaiting heart transplantation: sinking the lifeboat. JAMA Intern Med. 2015;175:1406-9.

Key Words: heart transplant, cardiac donor selection, organ utilization, transplant stewardship

\title{
EDITORIAL COMMENTARY
}

\section{Saying yes or saying no!}

\author{
Nicholas G. Smedira, MD
}

From the Department of Thoracic and Cardiovascular Surgery, The Cleveland Clinic Foundation, Cleveland, Ohio.

Disclosures: Author has nothing to disclose with regard to commercial support.

Received for publication Sept 15, 2015; accepted for publication Sept 16, 2015; available ahead of print Oct 27, 2015.

Address for reprints: Nicholas G. Smedira, MD, Department of Thoracic and Cardiovascular Surgery, The

Cleveland Clinic Foundation, 9500 Euclid Ave, Desk J41, Cleveland, OH 44195 (E-mail: smedirn@ ccf.org). J Thorac Cardiovasc Surg 2016;151:243-4

0022-5223/\$36.00

Copyright (c) 2016 by The American Association for Thoracic Surgery

http://dx.doi.org/10.1016/j.jtcvs.2015.09.073

In their article in this issue of the Journal, Smith and colleagues $^{1}$ from the University of Washington in Seattle demonstrate an impressive increase in donor heart use at both the transplant center and the local organ procurement organization through a multidisciplinary retrospective review of organ use practices. In the course of 3 years, their acceptance rate of offered hearts increased from $28 \%$ to $60 \%$, doubling the transplant volume without an increase in transplant-associated mortality. Whereas intercenter organ use is a zero-sum game, if each organ procurement organization could increase the organ use by $7 \%$ annually, an additional 150 hearts could be transplanted in the United States each year.

The readers are challenged to ascertain how Smith and colleagues made such dramatic changes. Smith and colleagues refer somewhat euphemistically to "behavioral

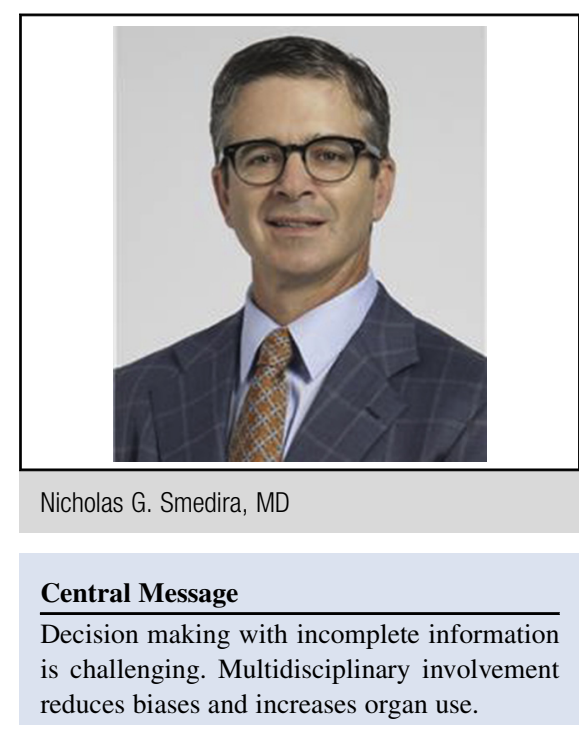

See Article page 238.

adaptation" and "frank discussions" regarding "individual and group bias" as explanations, but understanding exactly how this is accomplished is not easy.

In his number one best seller Thinking, Fast and Slow, Daniel Kahneman, ${ }^{2}$ (Nobel Prize in Economics in 2002) 